\title{
Electroless and Immersion Plating Process towards Structures and IMC Formation
}

\author{
M.A. Rabiatul Adawiyah ${ }^{1}$, O. Saliza Azlina ${ }^{* 1}$, Nor Akmal Fadil ${ }^{2}$, \\ Siti Rabiatull Aisha ${ }^{3}$, and M.A Azmah Hanim ${ }^{4}$ \\ ${ }^{1}$ Faculty of Mechanical and Manufacturing Engineering, \\ Universiti Tun Hussein Onn Malaysia, Batu Pahat, Johor, Malaysia \\ ${ }^{2}$ Faculty of Mechanical Engineering, Universiti Teknologi Malaysia, Johor Bahru, Johor, Malaysia \\ ${ }^{3}$ Faculty of Mechanical Engineering, Universiti Malaysia Pahang, Pekan, Pahang, Malaysia \\ ${ }^{4}$ Faculty of Engineering, Universiti Putra Malaysia, Serdang, Selangor, Malaysia \\ ${ }^{1}$ rabiatuladda90@gmail.com; ${ }^{*}$ salizaz@uthm.edu.my \\ 2norakmal@fkm.utm.my \\ 3 rabiatull@ump.edu.my \\ 4azmah@upm.edu.my
}

\begin{abstract}
The selection of surface finish on printed circuit board is very important in soldering process because it can prevent the copper from oxidation and provide solderable surface. It is also will influence the cost, manufacturing, shelf life, surface quality, final product reliability and environment.Electroless and immersion plating process has now become an important and popular surface finish in electronic industry due to simple and low cost process. The application of electroless plating are widely used in electronic industry, however it also was used in various industries such as aerospace, automotive, oil and gas, chemical processing where the need on the complex shape, homogeneous and uniform layer are required. Besides, every surface finish has their strength and weakness. Immersion silver is one of the surface finishes frequently used on the printed circuit board due to their characteristics such as good solderability and wettability, easy assembly and low cost. Both of these two processes were acts as barrier layer between copper substrate and solder balls. This review was discussed about electroless nickel and immersion silver plated on copper substrate, coating process and parameters involved. The topic also covered include the morphology and thickness of the intermetallics formed during soldering as well as the isothermal aging process.
\end{abstract}

Keyword - Electroless plating, Electroless nickel, Immersion silver, Intermetallic compound, Reflow soldering

\section{INTRODUCTION}

The selection of surface finish on the printed circuit board could be the most important decision in electronic application. Currently, surface finish is used to protect the exposed copper surface from the oxidation when exposed to the environment which can reduce the strength of the solder joint and the wettability [1]. The electroless and immersion are widely used in electronic industry because both of them can enhanced the bond pad properties for electronic packaging [2]. The different between the electroless and immersion plating process are an auto-catalytic reaction [3-7] and displacement process [7], respectively. Electroless plating is a chemical reduction process $[4,5]$, where the deposition process of the metal was not involved the electrical energy usage [6,7]. Typical surface finishes commonly used for electroless plating technique are electroless nickel/immersion gold (ENIG) and electroless nickel/electroless palladium/immersion gold (ENEPIG). In electronic industry, electroless nickel (EN) is a popular surface finish compared to other techniques such as electroplating. Many researchers have been issued about the advantages of the EN for the engineering and especially for printed circuit board (PCB) application [3,5,7-9]. Several advantages of EN include the quality of deposit such as physical and mechanical properties. There are some of the properties were usable as solderability, high hardness, magnetic properties, resistivity and low coefficient of friction. However, most applications of the auto-catalytic are depend on their wear and corrosion resistance [3,7]. The desired properties can be a range by choosing different temperature, $\mathrm{pH}$ value and composition of the bath [3] as shown in Table 1.

The immersion plating is a displacement process where the metallic ions in the solution will be reduced on the surface substrates [7]. Immersion silver (ImAg) is one of important surface finish for the electronic assembly and it was Restriction of Hazardous Substances (RoHS) compliant. ImAg also known as an alternative to HASL [10-12] and ENIG [13,14] because of their good solderability, wettability, co-planarity and bonding performance [10,15]. According to Wang et al. [10], the selection of immersion silver as a final surface finish is a good decision because it can eliminates the embrittlement of Au-Sn intermetallic layer (IMCs) as well as provides simpler operation and lower cost. Furthermore, immersion plating are not required to use reducing agent because the base material can behaves as reducing agent compared to electroless plating process [16]. In this review, the present work aims to study the electroless and immersion plating process towards structures and 
intermetallic compound (IMC) formation including the coating process and its parameter, interfacial reaction between solder and substrates.

TABLE 1. Properties of Electroless Nickel Based Coatings [3]

\begin{tabular}{|l|c|c|c|}
\hline \multirow{2}{*}{ Property } & \multicolumn{3}{|c|}{ Coating System } \\
\cline { 2 - 4 } & Ni-3P & Ni-8P & Ni-0.5B \\
\hline Composition range: & & & \\
Balance nickel & $3-4 \% \mathrm{P}$ & $6-9 \% \mathrm{P}$ & $0.5-$ \\
Structure* & $\mathrm{m}-\mathrm{c}$ & $\mathrm{m}-\mathrm{c}-\mathrm{a}$ & $1.0 \% \mathrm{~B}$ \\
Final melting point & 1275 & 1000 & $\mathrm{c}$ \\
Density (gm/cm ${ }^{3}$ ) & 8.6 & 8.1 & 1440 \\
Electrical resistivity (mW-cm) & 30 & 75 & 8.6 \\
Thermal conductivity (W/cm- & 0.6 & 0.05 & 10 \\
K) & 1000 & $\mathrm{ND}$ & $\mathrm{ND}$ \\
Specific heat (J/kg-K) & 10000 & 110 & $\mathrm{ND}$ \\
Magnetic coercivity (A/m) & -10 & +40 & $\mathrm{ND}$ \\
Internal stress (MPa) & 300 & 900 & +500 \\
Tensile strength (MPa) & 0.7 & 0.7 & $\mathrm{ND}$ \\
Ductility (\%) & 130 & $100-120$ & $\mathrm{ND}$ \\
Modulus of elasticity (GPa) & & & ND \\
\hline
\end{tabular}

*a: amorphous; m-c: microcrystalline; m-c-a: mixed crystalline and amorphous;

c: crystalline; ND: not determined

\section{A. Introduction}

\section{ELECTROLESS NiCKEL PLATING}

Electroless nickel (EN) is produced from chemical reaction which involves nickel salts and reducing agent. The properties of electroless nickel are depending on the quantity of phosphorus in the chemical solution[6,17]. Generally, electroless plating process comprising a source of metal ions, complexing agent, reducing agent, stabilizer, buffering agent, wetting agent, controlled $\mathrm{pH}$ and temperature [6,7] as represented in Table 2. EN is a continuous process of metal deposition. Uniform thickness [5] and thick layer is obtained (between $3 \sim 6 \mu \mathrm{m}$ ) as long as the metal substrates still in nickel solution [6]. By controlling the chemical reduction of nickel ion, it is necessary to change the metal ions to the metal in order to form a coating layer on the substrate [7]. Besides that, if the parameter is not properly controlled, the unintended results will be happened because the reduction of nickel ion can take place in all solutions. The electroless plating process usually used to deposit metal or its alloys such as nickel, palladium, silver, gold and etc. to the substrate. Besides, either the nickel containing phosphorous or boron also included in this category [18]. The additional metal elements used in electroless deposition process known as poly alloy $[9,19]$. Some of binary, ternary and quaternary diagram are referred as poly alloys. For example, binary alloys have Ni-P [19] and Ni-B [20], while ternary alloys have Ni-P-B [20], and Ni-W-P [21]. For quaternary alloys have Ni-W-Cu-P [9,22]. Tables 3 represent the types of electroless metallic alloy coatings and their features.

In additional, electronic micro-component and packaging need a convenient barrier layer between $\mathrm{Cu}, \mathrm{Ag}$, $\mathrm{Al}, \mathrm{Ni}, \mathrm{Au}, \mathrm{Pd}$ and $\mathrm{Co}$ [7], as well as solder to perpetuate a long period of services. However, electroless nickel are found to be a suitable metal which can act as a barrier and protect the substrate due to it slowest pace rate dissolution of the solder and growth rate of the intermetallic compounds formation [24-28] compared to silver, gold or palladium. There are five types of EN coatings such as pure nickel, black nickel, electroless composite electroless nano-coatings and electroless nickel alloy coatings [7]. EN alloy coatings may consist four types, as follow [22]:

(1) Acid bath: Ni-P alloy, 3-5\% P (low), 6-9\% P (medium), 10-14\% P (high).

(2) Alkaline bath: Ni-P alloy.

(3) Acid bath: Ni-B alloy, 0.1-2\% B (low), 2.5\% B (medium), 5-10\% B (high).

(4) Alkaline bath: Ni-B alloy. 
TABLE 2. Summary Parameter of the Electroplating Solution and Their Function

\begin{tabular}{|l|l|}
\hline Parameter & \multicolumn{1}{|c|}{ Functions } \\
\hline Metal ions & $\begin{array}{l}\text { Sources of metal. For examples nickel sulphate, nickel acetates and } \\
\text { nickel chloride [7]. }\end{array}$ \\
\hline $\begin{array}{l}\text { Reducing } \\
\text { agent }\end{array}$ & $\begin{array}{l}\text { To supply electrons to reduce the metal ions. For example sodium } \\
\text { hypophosphite, amino boranes, sodium boron-hydride and hydrazine } \\
{[3,6,7,18] .}\end{array}$ \\
\hline $\begin{array}{l}\text { Complexing } \\
\text { agent }\end{array}$ & $\begin{array}{l}\text { To prevent access of free metal ions concentration, rapid pH change, } \\
\text { retard the inclination for precipitation of nickel salts. For example } \\
\text { EDTA, ammonia, dicarboxycarbo acids, alkanolamines, etc. } \\
{[6,7,18] .}\end{array}$ \\
\hline Stabilizer & $\begin{array}{l}\text { To stabilize the bath from decomposition by shielding. For examples } \\
\text { Pb, Sn, As, Mo, Cd, thiourea, etc. [6,7] }\end{array}$ \\
\hline $\begin{array}{l}\text { Buffering } \\
\text { agent }\end{array}$ & $\begin{array}{l}\text { Sustain the pH for long time. For example sodium salt and to choice } \\
\text { buffering agent depends on pH range used. For pH adjustment such } \\
\text { as sulphuric and hydrochloric acids, soda ammonia [7,17,23]. }\end{array}$ \\
\hline Temperature & \begin{tabular}{l} 
Energy for deposition [7]. \\
\hline
\end{tabular}
\end{tabular}

TABLE 3. Features and Types of Electroless Metallic Alloy Coatings [7]

\begin{tabular}{|l|l|}
\hline \multicolumn{1}{|c|}{ Consumption } & \multicolumn{1}{c|}{ Alloy types } \\
\hline Corrosion protection & Ni-P, Ni-P-Mo, Ni-Sn-P, Co-P, Co-P-Mo, Ni-Cu-P \\
\hline Wear resistance & $\begin{array}{l}\text { Ni-B, Ni-B-Tl, Ni-B-Mo, Ni-B-Sn, Co-P-W, Co-B; } \\
\text { Ni-P-SiC, Ni-P-WC (dispersion) }\end{array}$ \\
\hline Magnetic & Au-Ni, Au-Co; Ni-Co-P, Ni-Co-B, Ni-Fe-P \\
\hline Solderability & Sn-Pb, Ni-P \\
\hline High temperature & Co-W-B, Ni-Re-P \\
\hline Diffusion barrier & Ni-P \\
\hline
\end{tabular}

\section{B. Bath Chemistry}

\section{Reducing agent}

Some of reducing agents have been widely used in electroless plating including sodium hypophosphite, amino boranes, sodium borohydride and hydrazine $[3,6,7,18]$.

(1) Sodium hypophosphite

The most normally used to reduce agent was sodium hypophosphite. It is mainly used for electroless nickel plating because their characteristics can produce a nickel-phosphorus as a coating layer. Hypophosphite is capable to reduce nickel ions in solution to deposits nickel on metal substrate as well as on plastic substrates. More than $70 \%$ electroless nickel was deposited from solutions reduced by sodium hypophosphite $[7,18]$.

(2) Amino boranes

Amino boranes are versatility which is can avoid some issues with other borane reducing agent. $\mathrm{N}$ dimethyl amine borane (DMAB)- $\left(\mathrm{CH}_{3}\right)_{2} \mathrm{NHBH}_{3}$ and $\mathrm{N}$-diethylamide borane (DEAB)- $\left(\mathrm{C}_{2} \mathrm{H}_{5}\right)_{2} \mathrm{NHBH}_{3}$ are two types of amine boranes was used in electroless nickel plating solutions [3].

(3) Sodium borohydride

One of the powerful reducing agent was sodium borohydride, where available for the electroless nickel plating. Nickel boride will formed because of the presence of nickel ions. Borohydride is catalytically decomposed if the $\mathrm{pH}$ value above than 13 for alkaline solution and the reaction product is principally containing nickel. In general, $5 \mathrm{~kg}$ of hypophosphite is required while $0.6 \mathrm{~kg}$ of sodium borohydride is needed to reduce $1 \mathrm{~kg}$ of nickel [7]. However, complexing agents such as ethylenediamine must be used to prevent nickel hydroxide precipitation [3].

(4) Hydrazine

Using reducing agent such as hydrazine can produce pure electroless nickel deposition, which is contain up to $90 \%$ of nickel [7], with oxygen and $10 \%$ of nitrogen [22]. For the example, nickel chloride hexahydrate contain $4.8 \mathrm{gL}^{-1}, 32 \mathrm{gL}^{-1}$ of hydrazine and $4.6 \mathrm{gL}^{-1}$ of sodium tartrate dehydrate at $10 \mathrm{pH}$ values and $95^{\circ} \mathrm{C}$ of deposition. 


\section{Complexing agent}

Complexing agents are an organic acids. The function of this agent are to maintain stability of $\mathrm{pH}$ level, help to prevent precipitation of nickel salt such as phosphates and to reduce the concentration of free nickel ions [22]. Besides, this agent alsobuffer the solution that prevents a rapid $\mathrm{pH}$ change and retard the precipitation of nickel phosphate [6]. However, ammonia, hydroxides, carbonates may also have to be added periodically to neutralize the hydrogen [7].

\section{Stabilizer}

In general, stabilizer can control the plating reaction with added inhibitor (also known as stabilizer) in nickel plating bath solution. This additives have four types of stabilizer's concentration usually used in industries such as oxygen containing compounds $\left(\mathrm{AsO}^{-2}, \mathrm{MoO}_{2}\right.$, etc.), Compound of group IV elements ( $\mathrm{Se}, \mathrm{Te}$, etc.), heavy metal cations $\left(\mathrm{Sn}^{+2}, \mathrm{~Pb}^{+2}\right.$, etc.) and unsaturated organic acids (maleic, etc.) [6].

\section{Buffering agents}

Another family of additives is known as buffers. Buffers is a substance or joining of substance in solution. It is able to neutralizing both acids and base without changing the original of solution's $\mathrm{pH}$ [23]. The amount of acid was required to change the $\mathrm{pH}$ value to measure of buffer quantity. The common acids that used as buffer in electroless plating are including acetic, propionic, glutaric, succinic and adipic [17].

TABLE 4. Effect of pH Change on Electroless Nickel Plating Process [23]

\begin{tabular}{|l|l|l|}
\hline pH change & \multicolumn{1}{|c|}{ Effect on solution } & \multicolumn{1}{c|}{ Effect on deposition } \\
\hline Raise $\mathrm{pH}$ & $\begin{array}{l}\text { Lower phosphate solubility, } \\
\text { increased deposition rate. } \\
\text { Decreased stability with resultant } \\
\text { plate-out }\end{array}$ & $\begin{array}{l}\text { Decreased P content, shift in stress to } \\
\text { tensile direction. }\end{array}$ \\
\hline Lower pH & $\begin{array}{l}\text { The improvement of phosphate } \\
\text { solubility, the deposition rate is } \\
\text { decrease. }\end{array}$ & $\begin{array}{l}\text { Increased P content, shift in stress to } \\
\text { compressive direction. }\end{array}$ \\
Improved adhesion on steel. \\
\hline
\end{tabular}
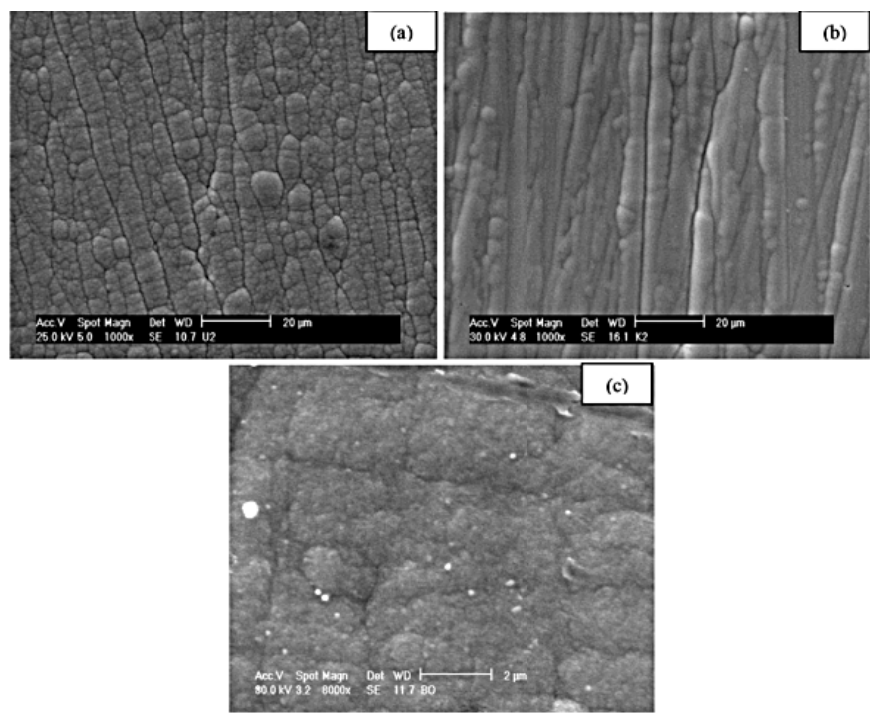

Fig. 1. SEM image top view of Ni-P with different P content (a) high Ni-P, (b) medium Ni-P and (c) low Ni-P [24]

Maintaining an EN solution begins with an understanding the chemical and physical process variable involved where it can influenced the bath process performance. These variablesalso can affect the quality of final deposition on copper board. Besides that, the condition of plating and sample preparation process also will influence the performance and quality of the EN plating.A consistent andstable solution during plating process is very important to provide high quality and uniform layer of nickel deposition on copper or PCB board.

\section{Nickel phosphorous}

Nickel phosphorous (Ni-P) alloy are commonly used for the deposition because it can let the thick coating onto the metal or substrates. Besides that, the bath solution is more stable during plating and better quality of coating 
can obtained [29]. The content of phosphorous in EN can influence the behaviour of the physical, mechanical and corrosion resistance properties of the coating. Oduoza and Khan [30] mentioned that the phosphorous content in EN can give effect on the internal stress because the existing internal stress depends on the microstructure Ni-P deposited. The parameter such as $\mathrm{pH}$ and temperature also can influence the rate of Ni-P deposition. It is an important to control the deposition rate of Ni-P or bath composition because when the $\mathrm{pH}$ decrease, the rate of deposition also decrease [31]. Table 4 shows the effect of $\mathrm{pH}$ change on EN plating process. According to Baldwin et al.[32], the temperature of plating bath will increased to the normal operating range when the content of phosphorous is decreased. Due to their properties, the phosphorous content may easy to control. The value of temperature also influences the rate of deposition. When the temperature increase, the plating rate also exponentially increases [23]. The increasing temperature more than $90^{\circ} \mathrm{C}$ make the $\mathrm{pH}$ value difficult to control $[31,5]$.

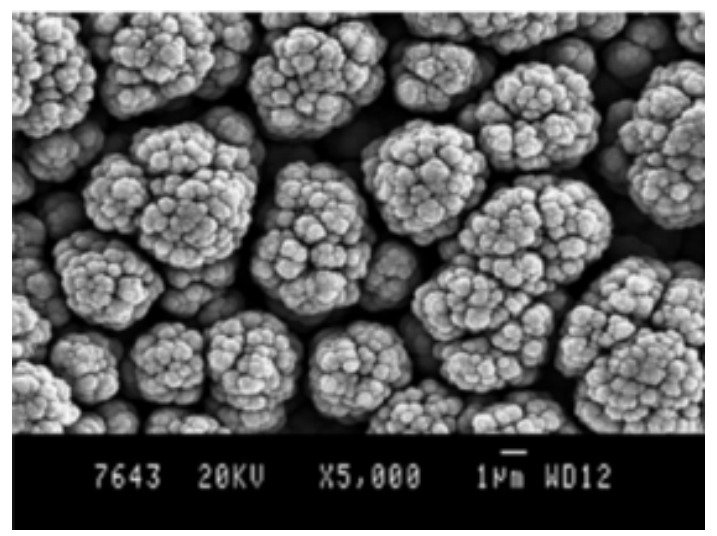

Fig. 2. SEM image of Ni-P morphology [34].

The growth structure of electroless nickel by using hypophosphate as reducing agent can be amorphous or liquid-like $[18,33]$. The amount of Ni-P can determine the microstructure of the coating either crystalline, amorphous, or both combination of microstructure [36]. Currently, electroless nickel process at low and medium phosphorus level has a mixture amorphous and microcrystalline nickel. While, the structure will be fully amorphous when the phosphorus content is high $[7,35,36]$ as showing in Fig. 1. Low Ni-P has created nodular shape (Fig. 1(c)), where it happened from combination granular type with grain boundaries. The grain boundaries affected the efficiency of low $\mathrm{P}$ as a diffusion barrier. These grain boundaries can be eliminated by using high P content nickel [24]. Schlesinger [22] also mentioned that the higher sizes of the nickel crystallites making up when the phosphorus content is lower. Thus, phosphorus can act as an inhibitor of crystal formation. At the temperature above $220-260^{\circ} \mathrm{C}$, the structure of Ni-P begins change and the deposits starts to crystalline and also lose its amorphous structure. Fig. 2 shows the microstructure of electroless Ni-P plating. Besides, the morphology of the structure is cauliflower-like and crystalline structure. Based on low phosphorous content, these coating have better wear resistant and excellent corrosion resistance in concentrated caustic soda. The abrasion resistance and corrosion protection are better enough as well as economical in plating bath work, if medium phosphorous was used. For the high phosphorous, the coatings have good corrosion resistant, very ductile [39], low porosity, low internal intrinsic stress and non-magnetic is as plated state [23].

\section{Solder Joint Microstructure of Ni-P coating}

During plating process, intermetallic compound (IMC) will never form because the phosphorus atoms are trapped between nickel atoms in random way. It is because, they can lessen the possibility of contact among nickel atoms $[18,38]$. After the plating process, the intermetallic layer will be formed as $\mathrm{Ni}_{3} \mathrm{P}$ within the alloy. $\mathrm{Ni}_{3} \mathrm{P}$ is a first intermetallic layer that forms after plating process. This formation will happen when the temperature raises $320^{\circ} \mathrm{C}$ as well as the crystallized structures will reach a maximum after heating at $400^{\circ} \mathrm{C}$ for 1 hour. Before the formation of $\mathrm{Ni}_{3} \mathrm{P}$ phase in stable condition, $\mathrm{NiP}_{2}$ and $\mathrm{Ni}_{12} \mathrm{P}_{5}$ can be form with medium and high phosphorous contents [7].

From the previous researchers $[39,40]$, the polycrystalline columnar structure of $\mathrm{Ni}_{3} \mathrm{P}$ has a contain defects. Kirkendall voids are defects that form on P-rich layer formation and these voids will be affected the joint reliability that cause brittle fracture. Alam et al. [43] reported that the content of P and thickness Ni-P layer probably effect the performing shear test. Normally, a new layer such as Ni-P rich is formed between interfacial IMC and pure electroless Ni-layer during reflow process [44].

Normally, the type of IMC that formed after reflow soldering between substrates and solder balls was $\left(\mathrm{Cu}, \mathrm{Ni}_{6} \mathrm{Sn}_{5}\right.$. The formation of intermetallic compound between solder and Ni-P are depending on $\mathrm{Cu}$ concentration. If the $\mathrm{Cu}$ concentration in the solder was lower than $0.2 \mathrm{wt} \%$, only $(\mathrm{Ni}, \mathrm{Cu})_{3} \mathrm{Sn}_{4}$ appeared at the interface. Meanwhile, when the high concentration of $\mathrm{Cu}$ is more than $0.6 \mathrm{w} \%$ the IMC layer was $(\mathrm{Cu}, \mathrm{Ni})_{6} \mathrm{Sn}_{5}$. 
However, when the $\mathrm{Cu}$ concentration between $0.2 \mathrm{wt} \%$ and $0.6 \mathrm{wt} \%$, both $(\mathrm{Cu}, \mathrm{Ni})_{6} \mathrm{Sn}_{5}$ and $(\mathrm{Ni}, \mathrm{Cu})_{3} \mathrm{Sn}_{4} \mathrm{IMC}$ was detected [24,43-46]. Azlina et al. [49] was investigated about effect nickel doping on interfacial reaction between lead-free solder and Ni-P substrate. They found that only $(\mathrm{Cu}, \mathrm{Ni})_{6} \mathrm{Sn}_{5}$ was appeared at the interface after reflow soldering. Similar findings was reported by $[24,48,51]$. In addition, the formation of IMC at interface will be changed with reflow condition [45]. Fig. 3 shows the IMC $(\mathrm{Cu}, \mathrm{Ni})_{6} \mathrm{Sn}_{5}$ and $(\mathrm{Ni}, \mathrm{Cu})_{3} \mathrm{Sn}_{4}$ at interface between Ni-P with different content and $\mathrm{Sn}-4.0 \mathrm{Ag}-0.5 \mathrm{Cu}$ solder after reflow process. The typical structure of the IMC morphology is fine needle-type and boomerang-type [24].

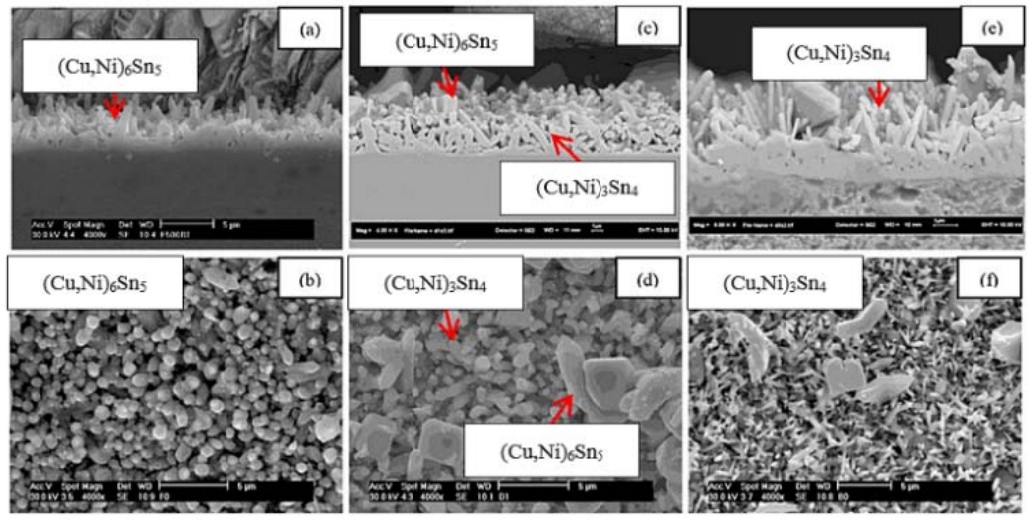

Fig. 3. Types of IMC at the interfaces between Ni-P and $\mathrm{Sn}-4.0 \mathrm{Cu}$ solder after reflow process: (a and b) high-P, (c and d) medium-P and (e and f) low-P [24].
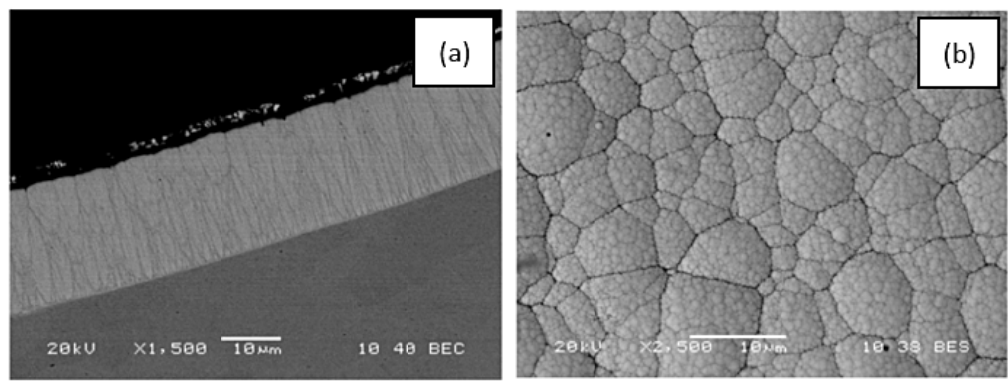

Fig. 4 The structure of Ni-B coating on top view (a) cross section columnar and (b) cauliflower-like surface [52].

To achieve a good performance standard of Ni-P deposition depends on the proper handling and correct operation. Surface preparation, operating parameter and chemistry solution are the main variables that influenced deposition rate, smoothness and uniform layer. The better understanding about the Ni-P plating process and their structure, it is easier to examine the crystallisation kinetic of the process with different phosphorous content. The different crystalline structure and IMC formation is depends on phosphorous content and reflow condition respectively. The first reaction between Ni-P deposits and subtracts is $\mathrm{Ni}_{3} \mathrm{P}$ layer. $\mathrm{Ni}_{3} \mathrm{P}$ layer is a thin layer that formed after plating process regardless of the phosphorous content. Currently, the type of IMC formationhas been determined by the type of lead-free solder, temperature, time and copper concentration. $(\mathrm{Cu}, \mathrm{Ni})_{6} \mathrm{Sn}_{5}$, and $(\mathrm{Ni}, \mathrm{Cu})_{3} \mathrm{Sn}_{4}$ are normally IMC that formed and found after reflow soldering process.

\section{D.Nickel-Boron}

The advantages of electroless Nickel-Boron (Ni-B) has gained the attention from manufacturer. This surface finish become popular in industry because of its ability to provide a high hardness, high wear, abrasion resistance and lubricity as well as excellent solderability [21,50,51]. The properties of electroless Ni-B found a significant interest in aerospace, automotive, chemical industries and electronics $[49,52,53]$. Besides that, the ability of Ni-B can act as capping layer to avoid the diffusion of $\mathrm{Cu}$ substrates and it is necessary in the $\mathrm{Cu}$ interconnects technology [57]. Commonly, reducing agent such as sodium borohydride or dimethyl-amine borane was used in Ni-B alloy. These reducing agent has superior mechanical and chemical properties compared with Ni-P deposits $[49,51-53,55]$.

In general, the phase of Ni-B consider as a mix amorphous and nano-crystalline because it is depending on boron content [55,56]. Similar reported by Delaunois and Lienard [60]. The structure of Ni-B present a typical cauliflower-like $[49,58]$ as showing in Fig. 4 . The formation of deposition Ni-B is begins by nodules, and then it was grows in columnar morphology. According to Rao et al. [56], the columnar morphology formed caused by the effect of the thickness of diffusion layer as illustrated in Fig. 5. These researchers also mentioned that the 
thicker of diffusion layer, growth at the edge of the columns where it is likely to be disturbed by convection than on their tops. Therefore, the morphology leads to the typical cauliflower-like surface.

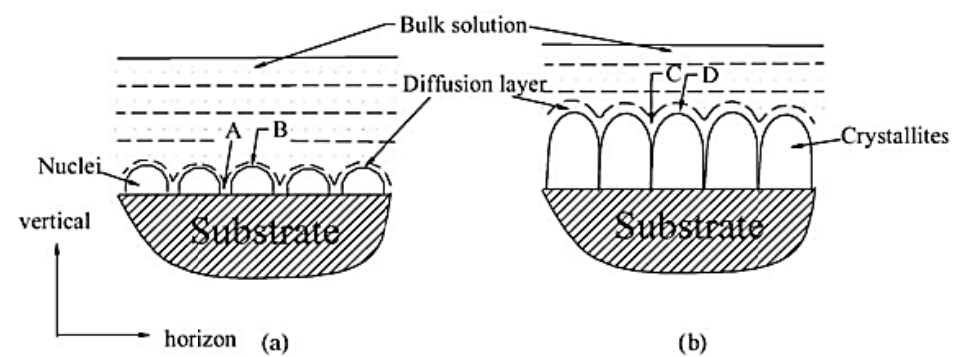

Fig. 5 The illustration for the effect of diffusion layer on top of Ni-B deposition (a) nucleation period and (b) crystallite growing period [56].
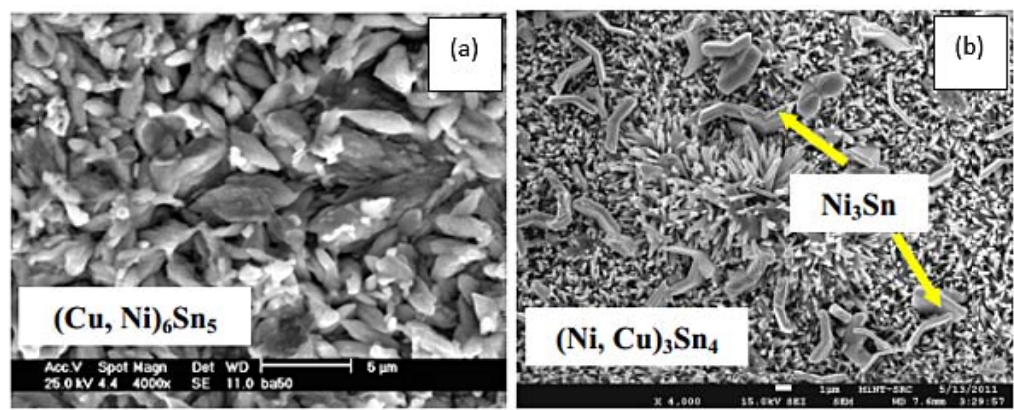

Fig. 6: SEM image top view of Sn-4Ag-0.5Cu between Ni-B after reflow soldering (a) near center area and (b) near outside area [62].

\section{Solder Joint Microstructure of Ni-B coating}

The first IMC layer of Ni-B will be leads to the crystallization of the $\mathrm{Ni}_{3} \mathrm{~B}$ phase and it happened after plating process $[7,49]$. When temperature above $250^{\circ} \mathrm{C}$, the structures of $\mathrm{Ni}-\mathrm{B}$ start crystalline and $\mathrm{Ni}_{3} \mathrm{~B}$ will form at temperature $370-380^{\circ} \mathrm{C}$ as well as $\mathrm{Ni}_{2} \mathrm{~B}$ [7]. Many researchers have been studied about interfacial reaction between lead-free solders and Ni-P [24,47,48,43-46]. Several of researcher also investigated about joint reliability and interfacial reaction between lead-free solder and Ni-B, but the knowledge about the structure and crystallization behaviour are still not yet clear $[6,7,21,50,51,61]$. The microstructure of the Ni-B is not too much different with Ni-P. Aisha et al. [64] was investigated about interfacial reaction of lead free solder on electroless $\mathrm{Ni}-\mathrm{P} / \mathrm{ImAu}$ and $\mathrm{Ni}-\mathrm{B} / \mathrm{ImAu}$. They found that the formation of IMC layer after reflow process were $(\mathrm{Cu}, \mathrm{Ni})_{6} \mathrm{Sn}_{5}$ for both electroless Ni-P and Ni-B respectively. However, the IMC layer of $(\mathrm{Ni}, \mathrm{Cu})_{3} \mathrm{Sn}_{4}$ wasdetected at interface between $(\mathrm{Cu}, \mathrm{Ni})_{6} \mathrm{Sn}_{5}$ and $\mathrm{Ni}_{3} \mathrm{P}$ after exposure in isothermal aging process. According to Azlina et al. [62], there are two types of IMC was formed between SAC405/EN(B)EPIG after reflow soldering. $(\mathrm{Ni}, \mathrm{Cu})_{3} \mathrm{Sn}_{4}$ was observed at the near outside area of the solder ball meanwhile, $\left(\mathrm{Cu}, \mathrm{Ni}_{6} \mathrm{Sn}_{5}\right.$ was found at the near center area as can be seen in Fig. 6. Both IMC was continuously growth when subjected to isothermal aging.

\section{III.PLATING PROCESS OF IMMERSION SILVER}

\section{A. Introduction}

The immersion plating is a process where the chemical displacement reaction will be deposited into the bare copper. During the reaction, the base metal donates the electrons that can reduce the positive charge metal ions which present in solution. During the reaction, once the metal is plated, there is no any source of electrons and the reaction will automatically stopped. Therefore, this reaction is considered as a self-timing process [65]. The ImAg process consist the cleaning, micro-etching, pre-dipping, immersion silver deposition. The function of each steps of ImAg process has been presented in Table 5. During ImAg process, the operating parameter such as $\mathrm{pH}$, temperature and solution very important to get the best surface finish. These parameters will be affected to the transfer dynamics at the plating surface [66]. 
TABLE 5. The Function of Each Steps Immersion Silver [10]

\begin{tabular}{|l|l|}
\hline Process & Function \\
\hline Cleaner & $\begin{array}{l}\text { To clean the copper surface before the next process. } \\
\text { Removes surface oils, oxides, any organic material } \\
\text { and to ensure the copper surface will be in good } \\
\text { condition and to be uniformly micro-etch. }\end{array}$ \\
\hline Micro-etching & $\begin{array}{l}\text { To produce a plating surface that promotes good } \\
\text { deposit adhesion. Remove any chemical contaminant } \\
\text { and metal oxides by lightly etching the exposed } \\
\text { copper surface. The example of etchant types are } \\
\text { sodium per-sulphate, peroxide / sulphuric. }\end{array}$ \\
\hline Pre-dipping & $\begin{array}{l}\text { To prevent any chemical residues from the previous } \\
\text { rinsing step and remove any surface oxidation that } \\
\text { may happen in the previous rinsing stage. }\end{array}$ \\
\hline $\begin{array}{l}\text { Immersion } \\
\text { silver } \\
\text { deposition }\end{array}$ & $\begin{array}{l}\text { To deposits a layer of silver onto all of the exposed } \\
\text { copper surface and protect copper from oxidation. }\end{array}$ \\
\hline $\begin{array}{l}\text { Drying } \\
\text { process }\end{array}$ & $\begin{array}{l}\text { To ensure the copper with silver surface finish are } \\
\text { completely dry. Remove any leftovers moisture from } \\
\text { the board to prevent discolour and to ensure metal } \\
\text { quality. }\end{array}$ \\
\hline
\end{tabular}

\section{B. Characteristics of the Immersion Silver Surface Finish}

Immersion silver ( $\operatorname{ImAg}$ ) is one of an alternative finish where it was designed as protective surface finish to ensure the solderability of the underlying substrate $[10,15]$. The advantages of ImAg finish including good coplanarity, wire bondable [15], and suitable for fine-pitch of electronic applications [67]. According to Barbetta [67], ImAg also has good solderability, and it can maintained through the multiple reflow cycles. Besides that, it is also can maintaining thesolderability or wettability until 12 months before assembly process [12].

During soldering process, ImAg will be dissolved into the molten solder during assembly process because of liquidation of silver into the tin (Sn) based in the solder [10,15] as shown in Fig 7 (a). The thickness of Ag layer is typically less than $1 \mu \mathrm{m}$. It is happen because the deposition of Ag process will be stopped when the substrate surface is fully covered with the Ag solution [15]. Furthermore, Cullen [68] stated that the ImAg consist of 0.15$0.55 \mu \mathrm{m}$ thickness layer and it is 100 times thinner than the traditional electroplated silver deposits. In addition, Wang et al. [10] found that in order to get the $0.5 \mu \mathrm{m} \mathrm{Ag}$ layer in range [69], the duration of plating time is around 1 minute to 4 minutes. The Association Connecting Electronics Industrial standard (IPC-4553) [70] stated that the recommended thickness of $\mathrm{Ag}$ layer as minimum $0.13 \mu \mathrm{m}$ and typically $0.2 \mu \mathrm{m}-0.3 \mu \mathrm{m}$ can be obtained by using $60 \times 60$ mil pad. The standard also indicated that the possibility to obtain Ag thickness from $0.07 \mu \mathrm{m}$ to $0.12 \mu \mathrm{m}$ is possible, but it may limited for general purpose application only [10,66]. Some researchers reported that the thickness of immersion silver must be not too thick due to brittle solder joint in lead-free soldering, and not too thin to ensure a lifespan of this surface finish during storage [70-72].

\section{Solder Joint Microstructure of Immersion Silver}

During reflow soldering, the interfacial reaction will occur between $\operatorname{ImAg}$ and solder. As the result, the layer of intermetallic compound (IMC) will be formed between them and provides a good metallurgical bonding [10]. The type of IMC layer will be formed at the interface is depends on the metal surface and solders were used. Thus, a selection of surface finish and solder type are playing an important role. 

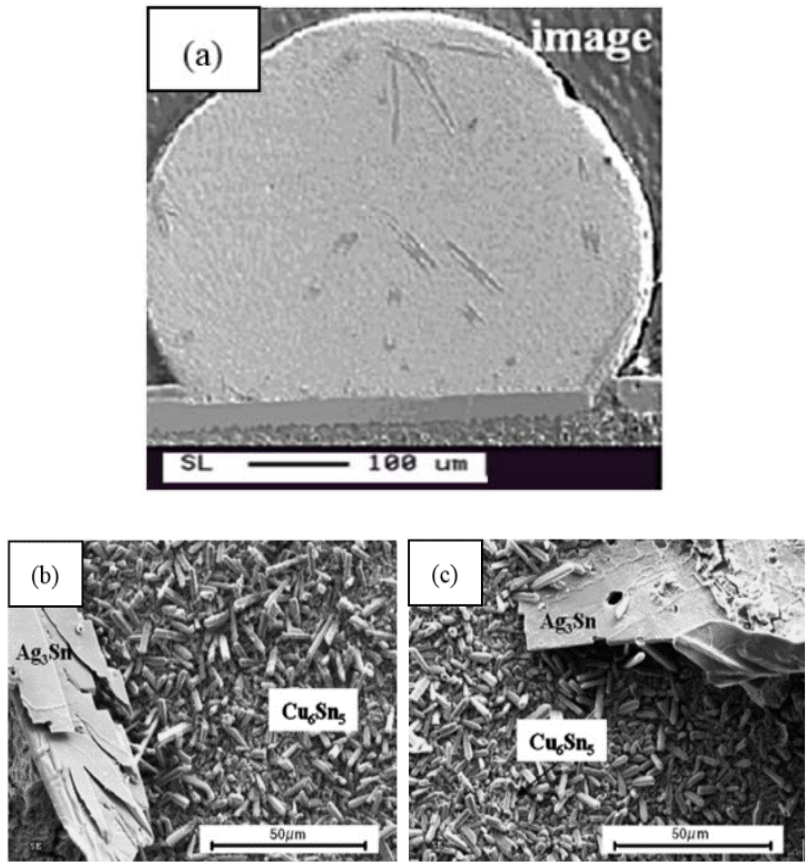

Fig. 7 SEM images of the Sn-3.5Ag-0.7Cu/ImAg plated joint reflowed at $250^{\circ} \mathrm{C}$ at $60 \mathrm{~s}$ : (a) solder joint surface, (b) and (c) top view of the interface between solder and substrate [72].

\section{The Formation of Intermetallic Growth}

Generally, the formation of IMCs such as $\mathrm{Cu}_{6} \mathrm{Sn}_{5}$ and $\mathrm{Cu}_{3} \mathrm{Sn}$ form at the interfaces. While, $\mathrm{Ag}_{3} \mathrm{Sn}$ compounds was appearedat the bulk solder. According to Yoon and Jung[72], the layer of $\mathrm{Cu}_{6} \mathrm{Sn}_{5}$ has been observed at the interface when reflowed the Sn-3.5Ag-0.7Cu with $\mathrm{ImAg}$ finish at $250^{\circ} \mathrm{C}$ for 60 seconds. The microstructure of the IMC layer in solder matrix comprised of a $\beta$-Sn matrix. A typical shape-type of the $\mathrm{Cu}_{6} \mathrm{Sn}_{5} \mathrm{was}_{\text {formed }}$ between the solder and ImAg interface after reflow process (Fig. 7 (b) and (c)). The morphology of $\mathrm{Cu}_{6} \mathrm{Sn}_{5}$ is rods-like, while $\mathrm{Ag}_{3} \mathrm{Sn}$ is plates-like [72]. Zheng et al. [65] was investigated the similar surface finish with $\mathrm{Sn}-$ $3.8 \mathrm{Ag}-0.7 \mathrm{Cu}$. They also found a large $\mathrm{Ag}_{3} \mathrm{Sn}$ platelet or needles are currently above the $\mathrm{Cu}_{6} \mathrm{Sn}_{5}$ layer after reflow process. Wiese et al.[73] was studied about the microstructure of Sn-4.0Ag-0.5Cu, they found that the formation of $\mathrm{Ag}_{3} \mathrm{Sn}$ and $\mathrm{Cu}_{6} \mathrm{Sn}_{5}$ in a matrix of tin. Similar results have obtained by Lee et al.[74]. However, the $\mathrm{Ag}_{3} \mathrm{Sn}$ platelet will be disappeared from the interface after exposed to high temperature aging and a new thin layer $\mathrm{Cu}_{3} \mathrm{Sn}$ will be appeared between the interface substrate and $\mathrm{Cu}_{6} \mathrm{Sn}_{5}$. It was happened because of atomic diffusion between copper atoms and tin atoms from the solder [10,75].

Based on $\mathrm{Cu}-\mathrm{Sn}$ phase diagram, IMC phase of $\mathrm{Cu}_{6} \mathrm{Sn}_{5}$ is form from the liquid solder state and the $\mathrm{Cu}_{3} \mathrm{Sn}$ phase will be formed during inter-diffusion between interface copper and the $\mathrm{Cu}_{6} \mathrm{Sn}_{5}$ layer. Prior to aging process, the morphology of IMC is scalloped, but after exposed to aging it becomes thicker and uniform [69]. The different of aging times can influence the thickness of IMC layers either $\mathrm{Cu}_{6} \mathrm{Sn}_{5}$ or $\mathrm{Cu}_{3} \mathrm{Sn}$ because the increasing of IMC layers with increasing aging time. Korhonen et al.[76] also investigated the thickness of the IMC layer. These researchers stated that the thickness of IMCs is depends on the solder sizes. The small solder balls will produced thicker IMC compared to the bigger solder balls. This is because the small solder will saturates quickly and caused the fast growth of IMCs.

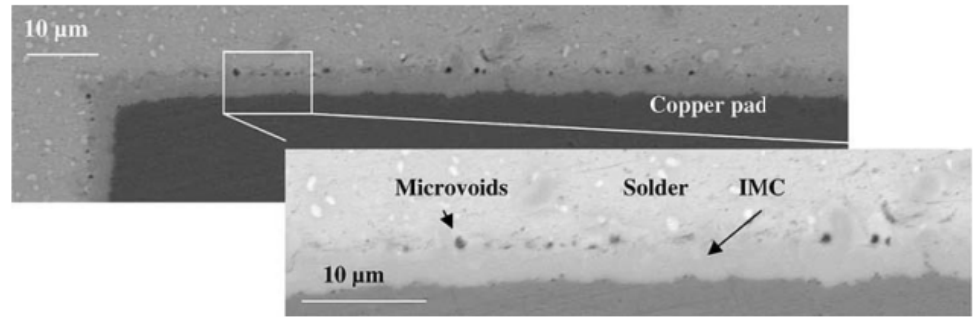

Fig. 8 Immersion silver pad finish with Sn-3.0Ag-0.5Cu solder joint; microvoids were found at the interface of solder and IMC layer [10]. 


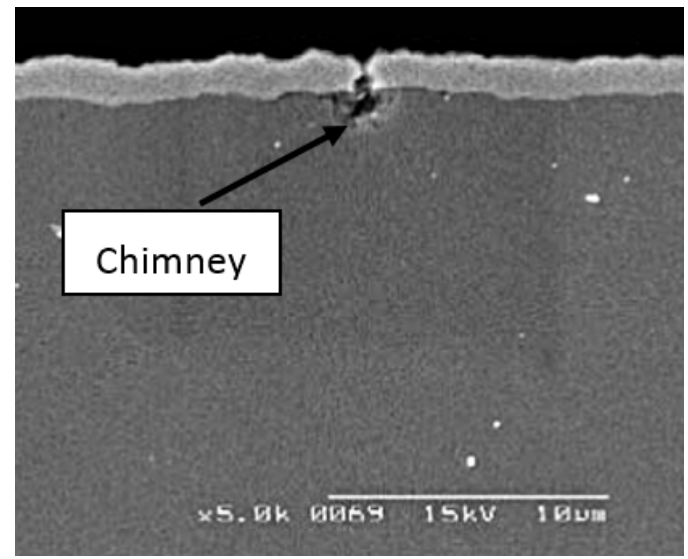

Fig. 9 The formation of chimney at a pathway between caves and silver surface [77]

\section{The Formation of Microvoiding}

A small holes (smaller than $50 \mu \mathrm{m}$ ) that form in a solder joint knows as microvoids (champagne voids) [78] as showing in Fig. 8. These voids caused by the unbalanced inter-diffusion ofcopper and tin at the interface between substrates and solder [10]. According to Schueller [79] and Yau et al. [78], the formation of microvoids caused by cavities or empty bubbles in the copper (the source of the microvoids upon reflow) It is happened because of the interaction between silver and copper during silver plating process $[11,75,76]$.

Furthermore, the thicker silver layer can influence microvoid formation [78]. Typically, voids will form at near the surface of the copper pad, where the silver layer was used. The size of microvoids can separated into two groups which are small microvoids for the diameter less than the thickness of IMC layer (about $5 \mu \mathrm{m}$ ), while large microvoids for diameter greater than the thickness of IMC layer (less than $25 \mu \mathrm{m}$ ) [78]. The existence of microvoids can affect the solder joint strength [80], reliability and lead to crack propagation [10]. Besides that, the chemical solution during plating process has to be maintained, followed the specifications and guidelines to prevent the possibility of microvoid formation [80].

Previous researcher has found the "caves" under the immersion silver coating (Fig. 9). The formation of cave happened due to contaminant of inorganic residues material on the copper substrates during plating process [78]. Once the cave will be appeared at the surface, the microvoids formation have high tendency to occur during assembly. Besides that, Cullen et al. [78] discussed that a chimney formation was detected between caves and silver layer. Chimney is a micro pore that connecting the cave to the surface. However, the formation of cave can be reduced by modify the pre-sulphate micro etches solution.

ImAg finish proves to be high performing and low cost and allowed as alternative to both of HASL and ENIG because of a simpler process. Using the immersion process, the layer was uniform and met the thickness criteria and very stable process because the reaction only based on replacement process. It is also a better choice for lead-free electronics application that has good wettability and solderability compared to other lead free surface finishes. During reflow process, the layer of $\mathrm{Cu}_{6} \mathrm{Sn}_{5}$ and $\mathrm{Ag}_{3} \mathrm{Sn}$ are growing into the solder. When the solder exposed to the aging process, $\mathrm{Cu}_{3} \mathrm{Sn}_{4}$ layer was appeared and $\mathrm{Ag}_{3} \mathrm{Sn}$ platelet disappeared (with the high temperature aging) from the interface of solder. However, the defect known as microvoid and cave formation has been observed at near surface of copper substrate under silver layer coating, however the prevention can be made by maintained and controlled the chemical plating during the immersion silver process.

\section{IV.CONCLUSION}

Plating process involves covering outer layer of the copper or PCB board by deposition process. It is act as barriers to prevent corrosion and to improve the surface finish appearance. Every plating process required advantages from process control because it is very important to achieve the desired properties such as physical and mechanical properties as well as to getting quality of deposits. Besides, two crucial parameter such as $\mathrm{pH}$ value and temperaturewere affectedthe performance of plating process. This review paper has presented two plating process namely electroless nickel and immersion silver plating including their structures and IMC formation, by various researchers are reviewing the variety of informations.ENhas two types namely Ni-P and $\mathrm{Ni}-\mathrm{B}$. Both of Ni-P and Ni-B crystalline structures formation depended on the amount of $\mathrm{P}$ and $\mathrm{B}$ content. The different both of these content, the different structures will be appeared either the structure are amorphous, crystalline or amorphous and crystalline. While, the ImAg surface finish is an alternative to both HASL and ENIG due to excellent wettability, simple process and economical. There are several types of IMC that formed after reflow soldering for $\mathrm{EN}$ and $\mathrm{ImAg}$ such as $(\mathrm{Cu}, \mathrm{Ni})_{6} \mathrm{Sn}_{5},(\mathrm{Ni}, \mathrm{Cu})_{3} \mathrm{Sn}_{4}$ and $\mathrm{Cu}_{6} \mathrm{Sn}_{5}, \mathrm{Cu}_{3} \mathrm{Sn}_{4}$ for respectively. The thickness and size of microstructure of IMC layer influenced by reflow condition, solder size and aging 
time. The increasing of aging duration made IMC layer also increased. Meanwhile, the bigger solder ball sizes produced a thinner IMC layer compared with smallest solder ball sizes where produced thicker IMC layer.

\section{ACKNOWLEDGMENT}

The authors gratefully acknowledge the financial support by the Ministry of Education Malaysia and Universiti Tun Hussein Onn Malaysia. This research is supported by FRGS Vot No. 1493.

\section{REFERENCES}

[1] L. M. Toscano and E. Long, "A New Surface for the Electronics Industry Electroless Nickel/Immersion Silver," IEEE Trans. Components Packag. Technol., pp. 372-378, 2005.

[2] I. M. P. Doyle, G. Dale, H. Choi, and B. City, "UnIted States Patent 6,974,776 B2," 2012.

[3] R. C. Agarwala and V. Agarwala, "Electroless alloy / composite coatings: A review," Sadhana, vol. 28, no. August, pp. 475-493, 2003.

[4] A. Brenner and G. E. Riddell, "Nickel plating on steel by chemical reduction," J. Res. Natl. Bur. Stand. (1934)., vol. 37, no. 1, p. 31, 1946.

[5] K. Krishnan, S. John, K. Srinivasan, J. Praveen, M. Ganesan, and P. Kavimani, "An overall aspect of electroless Ni-P depositions-A review article," Metall. Mater. Trans. A, vol. 37, no. 6, pp. 1917-1926, 2006.

[6] S. Sapkal, A. Bhagwat, D. Bendrikar-shinde, Z. Vadhwania, R. Gondil, and R. Waikar, "Parametric Analysis of Electroless Nickel Plating - A Review," no. March, 2015.

[7] J. Sudagar, J. Lian, and W. Sha, "Electroless Nickel, Alloy, Composite and Nano Coatings-A Critical Review," J. Alloys Compd., vol. 571, pp. 183-204, 2013.

[8] J. N. Balaraju, S. K. Seshadri, M. S. Division, N. A. Laboratories, and M. Centre, "Electroless Ni - P composite coatings," J. Appl. Electrochem., vol. 33, no. 51, pp. 807-816, 2003.

[9] P. Sahoo and S. K. Das, "Tribology of electroless nickel coatings - A review," Mater. Des., vol. 32, no. 4, pp. 1760-1775, 2011.

[10] W. Wang, A. Choubey, M. H. Azarian, and M. Pecht, "An assessment of immersion silver surface finish for lead-free electronics," in Journal of Electronic Materials, 2009, vol. 38, no. 6, pp. 815-827.

[11] R. Schueller, "Creep Corrosion on Lead-Free Printed Circuit Boards in High Sulfur Environments," SMTA Int. Proc., pp. 1-9, 2007.

[12] Y. Zhou and M. Pecht, "Reliability Assessment of Immersion Silver Finished Circuit Board Assemblies Using Clay Tests," IEEE Trans. Components Packag. Technol., pp. 1212-1216, 2009.

[13] K. Y. Lee, M. Li, and K. N. Tu, "Growth and ripening of ( $\mathrm{Au}, \mathrm{Ni}$ ) Sn 4 phase in $\mathrm{Pb}$-free and $\mathrm{Pb}$-containing solders on $\mathrm{Ni} / \mathrm{Au}$ metallization,” J. Mater. Res., vol. 18, no. 11, pp. 2562-2570, 2003.

[14] G. Ghosh, "Dissolution and interfacial reactions of thin-film Ti/Ni/Ag metallizations in solder joints," Acta Mater., vol. 49, no. 14, pp. 2609-2624, 2001.

[15] M. Arra, D. Shangguan, D. Xie, J. Sundelin, T. Lepistö, and E. Ristolainen, "Study of Immersion Silver and Tin Printed-Circuit-Board Surface Finishes in Lead-Free Solder Applications," J. Electron. Mater., vol. 33, no. 9, pp. 977-990, 2004.

[16] A. Brenner and G. Riddell, "Deposition of nickel and cobalt by chemical reduction," J. Res. Natl. Bur. Stand. (1934)., vol. 39, no. November, p. 385, 1947.

[17] A. Małecki and A. Micek-Ilnicka, "Electroless nickel plating from acid bath," Surface and Coatings Technology, vol. 123, no. 1. pp. $72-77,2000$.

[18] Y. WANG, C. XIAO, and Z. DENG, "Structure and corrosion resistance of electroless Ni-Cu-P," Plat. Surf. Finish., vol. 79, no. 3, pp. $57-59,1992$.

[19] M. Palaniappa and S. K. Seshadri, "Friction and wear behavior of electroless Ni-P and Ni-W-P alloy coatings," Wear, vol. 265, no. 56, pp. 735-740, 2008.

[20] K. N. Srinivasan, R. Meenakshi, a. Santhi, P. R. Thangavelu, and S. John, "Studies on development of electroless Ni-B bath for corrosion resistance and wear resistance applications," Surf. Eng., vol. 26, no. 3, pp. 153-158, 2010.

[21] J. N. Balaraju and K. S. Rajam, "Electroless deposition of Ni-Cu-P, Ni-W-P and Ni-W-Cu-P alloys," Surf. Coatings Technol., vol. 195, no. 2-3, pp. 154-161, 2005.

[22] M. Schlesinger, "Electroless Deposition of Nickel,” Mod. Electroplat. Fifth Ed., vol. 4, no. 3, pp. 447-458, 2011.

[23] G. O. Mallory, "The electroless nickel plating bath: effect of variables on the process," Electroless plating, Fundam. Appl., p. 69; 71; $72,2009$.

[24] I. Siti Rabiatul Aisha, A. Hanim, M. Ariff, A. Ourdjini, and O. Saliza Azlina, "Development of Diffusion Barrier Layer On CopperPrinted Circuit Board Using Electroless Nickle Plating Method,” vol. 3, no. 4, pp. 329-339, 2015.

[25] S. L. Tay, A. S. M. A. Haseeb, M. R. Johan, P. R. Munroe, and M. Z. Quadir, "Influence of Ni nanoparticle on the morphology and growth of interfacial intermetallic compounds between Sn-3.8Ag-0.7Cu lead-free solder and copper substrate," Intermetallics, vol. 33, pp. $8-15,2013$

[26] S. A. Osman, A. Ourdjini, S. R. A. Idris, and A. H. Mohd Ariff, "Effect of Different Aging Temperatures on Interfacial Reaction between SAC305 and ENEPIG Surface Finish," Adv. Mater. Res., vol. 415-417, pp. 1181-1185, 2011.

[27] D. Baudrand and J. Bengston, "Electroless Plating Processes - Developing Technologies for Electroless Nickel, Palladium and Gold," Met. Finish, no. 93, pp. 55-57, 1995.

[28] M. a. Azmah Hanim, A. Ourdjini, O. Saliza Azlina, and S. R. Aisha, "Intermetallic Evolution for Isothermal Aging Up To 2000 Hours On Sn-4Ag-0.5Cu and Sn-37Pb Solders With Ni/U Layers," Automot. Mech. Eng., vol. 8, no. December, pp. 1348-1356, 2013.

[29] G. O. Mallory and J. B. Hajdu, Electroless plating: fundamentals and applications. William Andrew, 1990.

[30] C. F. Oduoza and E. Khan, "Nickel-Phosphorus Deposition on Pretreated Aluminium Alloys during Immersion in Electroless Nickel Bath," Mater. Sci. Eng., vol. 1, pp. 457-471, 2011.

[31] J. H. Marshall, B. Laboratories, and M. Hill, "The Nickel Metal Catalyzed Decomposition of Aqueous Hypophosphite Solutions," Electrochem. Soc., vol. 130, no. 2, pp. 369-372, 1983.

[32] C. Baldwin and T. E. Such, "The plating rates and physical properties of electroless nickel/phosphorus alloy deposits," TRANS INST Met. Finish, vol. 46, no. 2, pp. 73-80, 1968.

[33] M. V Sullivan, J. H. Eigler, B. T. Laboratories, and M. H. L, "Electroless Nickel Plating for Making Ohmic Contacts to Silicon," J. Electrochem. Soc., vol. 104, no. 4, pp. 226-230, 1957. 
[34] R. Manish, Surface Engineering for Enhanced Performance against wear. 2013.

[35] J. P. Marton and M. Schlesinger, "The Nucleation, Growth, and Structure of Thin Ni-P Films," J. Electrochem. Soc., vol. 115, no. 1, p. $16,1968$.

[36] N. M. Martyak, "Characterization of Thin Electroless Nickel Coatings," Chem. Mater., vol. 6, no. 11, pp. 1667-1674, 1994.

[37] Z. Guo, K. G. Keong, and W. Sha, "Crystallisation and phase transformation behaviour of electroless nickel phosphorus platings during continuous heating," J. Alloys Compd., vol. 358, no. 1-2, pp. 112-119, 2003.

[38] K. G. Keong, W. Sha, and S. Malinov, "Computer modelling of the non-isothermal crystallization kinetics of electroless nickelphosphorus deposits," J. Non. Cryst. Solids, vol. 324, no. 3, pp. 230-241, 2003.

[39] J. R. Henry, "Electroless (autocatalytic) plating," Met. Finish., vol. 105, no. 10, pp. 350-360, 2007.

[40] A. W. Goldenstein, W. Rostoker, F. Schossberger, and G. Gutzeit, "Structure of Chemically Deposited Nickel," J. Electrochem. Soc., vol. 104, no. 2, p. 104, 1957.

[41] A. Farzaneh, M. Mohammadi, M. Ehteshamzadeh, and F. Mohammadi, "Electrochemical and structural properties of electroless Ni-PSiC nanocomposite coatings," Appl. Surf. Sci., pp. 1-5, 2013.

[42] M. A. Rahmat, R. H. Oskouei, R. N. Ibrahim, and R. K. Singh Raman, "The effect of electroless Ni-P coatings on the fatigue life of Al 7075-T6 fastener holes with symmetrical slits," Int. J. Fatigue, vol. 52, pp. 30-38, 2013.

[43] M. O. Alam, Y. C. Chan, and K. C. Hung, "Reliability study of the electroless Ni - P layer against solder alloy," Microelectron. Reliab., vol. 42, pp. 1065-1073, 2002.

[44] I. S. R. Aisha, A. Ourdjini, M. A. A. Hanim, and O. S. Azlina, "Effect of reflow soldering profile on intermetallic compound formation,” Int. J. Comput. Appl. Technol., vol. 52, no. 4, p. 244, 2015.

[45] J. Yoon and S. Jung, "Interfacial reactions between $\mathrm{Sn}-0.4 \mathrm{Cu}$ solder and $\mathrm{Cu}$ substrate with or without ENIG plating layer during reflow reaction," Alloy. Compd., vol. 396, pp. 122-127, 2005.

[46] S. J. Wang and C. Y. Liu, "Study of interaction between Cu-Sn and Ni-Sn interfacial reactions by Ni-Sn3.5Ag-Cu sandwich structure," J. Electron. Mater., vol. 32, no. 11, pp. 1303-1309, 2003.

[47] C.-S. Huang, G.-Y. Jang, and J.-G. Duh, "Soldering-induced Cu diffusion and intermetallic compound formation between Ni/Cu under bump metallization and SnPb flip-chip solder bumps," J. Electron. Mater., vol. 33, no. 4, pp. 283-289, 2004.

[48] P. Sun, C. Andersson, X. Wei, Z. Cheng, D. Shangguan, and J. Liu, "High temperature aging study of intermetallic compound formation of $\mathrm{Sn}-3.5 \mathrm{Ag}$ and $\mathrm{Sn}-4.0 \mathrm{Ag}-0.5 \mathrm{Cu}$ solders on electroless $\mathrm{Ni}(\mathrm{P})$ metallization," J. Alloys Compd., vol. 425, no. 1-2, pp. 191$199,2006$.

[49] O. S. Azlina, A. Ourdjini, and I. S. R. Aisha, "Effect of Nickel Doping on Interfacial Reaction between Lead-Free Solder and Ni-P Substrate," Adv. Mater. Res., vol. 488-489, pp. 1375-1379, 2012.

[50] P. Yao, P. Liu, and J. Liu, "Interfacial reaction and shear strength of $\mathrm{SnAgCu}-\mathrm{xNi} / \mathrm{Ni}$ solder joints during aging at 150 ??C," Microelectron. Eng., vol. 86, no. 10, pp. 1969-1974, 2009.

[51] M. A. A. Hanim, A. Ourdjini, I. S. R. Aisha, and O. S. Azlina, "Effect of Isothermal Aging 2000 Hours on Intermetallics Formed between Ni-Pd-Au with Sn-4Ag-0.5Cu Solders," Adv. Mater. Res., vol. 650, pp. 194-199, 2013.

[52] V. Vitry, A. F. Kanta, and F. Delaunois, "Mechanical and wear characterization of electroless nickel-boron coatings," Surf. Coatings Technol., vol. 206, no. 7, pp. 1879-1885, 2011.

[53] K. Krishnaveni, T. S. N. Sankara Narayanan, and S. K. Seshadri, "Electroless Ni-B coatings: Preparation and evaluation of hardness and wear resistance," Surf. Coatings Technol., vol. 190, no. 1, pp. 115-121, 2005.

[54] T. S. N. Sankara Narayanan and S. K. Seshadri, "Formation and characterization of borohydride reduced electroless nickel deposits," J. Alloys Compd., vol. 365, no. 1-2, pp. 197-205, 2004.

[55] Y. W. Riddle and T. O. Bailer, "Friction and wear reduction via an Ni-B electroless bath coating for metal alloys," J. Miner. Met. Mater. Soc., vol. 57, no. 4, pp. 40-45, 2005.

[56] Q. L. Rao, G. Bi, Q. H. Lu, H. W. Wang, and X. L. Fan, "Microstructure evolution of electroless Ni-B film during its depositing process," Appl. Surf. Sci., vol. 240, no. 1-4, pp. 28-33, 2005.

[57] M. Tsujimura, H. Inoue, H. Ezawa, M. Miyata, and M. Ota, "Ni - B Electroless Plating as Cap Layer for Ag Multi-Level Metallization *," Mater. Trans., vol. 43, no. 7, pp. 58-63, 2002.

[58] C. T. Dervos, J. Novakovic, and P. Vassiliou, "Vacuum heat treatment of electroless Ni-B coatings," Mater. Lett., vol. 58, no. 5, pp. 619-623, 2004

[59] S. Ziyuan, W. Deqing, and D. Zhimin, "Nanocrystalline Ni-B coating surface strengthening pure copper," Appl. Surf. Sci., vol. 253, no. 3, pp. 1051-1054, 2006.

[60] F. Delaunois and P. Lienard, "Heat treatments for electroless nickel - boron plating on aluminium alloys," Surf. Coatings Technol., vol. 160, pp. 239-248, 2002.

[61] A. Contreras, C. Le??n, O. Jimenez, E. Sosa, and R. P??rez, "Electrochemical behavior and microstructural characterization of 1026 Ni-B coated steel,” Appl. Surf. Sci., vol. 253, no. 2, pp. 592-599, 2006.

[62] O. Saliza Azlina, A. Ourdjini, and M. H. I. Ibrahim, "Comparison between SAC405 Lead-Free Solders and EN(P)EPIG and EN(B)EPIG Surface Finishes," Appl. Mech. Mater., vol. 773-774, pp. 232-236, 2015.

[63] O. Saliza Azlina, A. Ourdjini, A. Amrin, and I. Siti Rabiatull Aisha, "Effect of Solder Volume on Interfacial Reaction between SAC405 Solders and EN(B)EPIG Surface Finish,” Adv. Mater. Res., vol. 845, pp. 76-80, 2013.

[64] S. R. Aisha, A. Ourdjini, N. . Wah, H. . How, and Y. T. Chin, "Interfacial Reactions of SAC305 and SAC405 Solders on Electroless $\mathrm{Ni}(\mathrm{P}) /$ Immersion $\mathrm{Au}$ and Electroless $\mathrm{Ni}(\mathrm{B}) /$ Immersion Au Finishes," Technology, pp. 2-7, 2010.

[65] Association Connecting Electronics Industrial, "IPC-4553. Specification for Immersion Silver Plating for PCB," 2005.

[66] M. D. Charyk, T. Tyson, E. Stafstrom, R. Morrissey, and C. Ri, "Optimizing Immersion Silver Chemistries for Copper Chart 1: Proportional Cost HASL Alternatives," IPC Print. Circuits Expo, 2008.

[67] M. Barbetta, "The search for the universal surface finish," Print. Circuit Des. Manuf., vol. 21, no. 2, pp. 34-43, 2004.

[68] D. P. Cullen and G. O’Brien, "Implementation of immersion silver PCB surface finish in compliance with Underwriters Laboratories," IPC Print. Circuits Expo, no. October 2001, pp. 1-10, 2004.

[69] P. Zheng, Y., Hillman, C., McCluskey, "Intermetallic Growth on PWBs Soldered with Sn3.8Ag0.7Cu," Electron. Components Technol. Conf. 2002. Proceesings.52nd, pp. 1226-1231, 2002.

[70] Association Connecting Electronics Industrial, "IPC-4553. Specification for Immersion Silver Plating for PCB," no. February, 2005.

[71] G. Milad, "Surface finishes in a lead-free world," Circuit World, vol. 34, no. 4. pp. 4-7, 2008. 
[72] J. W. Yoon and S. B. Jung, "Effect of immersion Ag surface finish on interfacial reaction and mechanical reliability of Sn-3.5Ag0.7Cusolder joint," J. Alloys Compd., vol. 458, no. 1-2, pp. 200-207, 2008.

[73] S. Wiese, A. Schubert, H. Walter, R. Dudek, and F. Feustel, "Constitutive Behaviour of Lead-free Solders vs . Lead-containing Solders - Experiments on Bulk Specimens and Flip-Chip Joints," 51St Electron. Components Technol. Conf., vol. 00, no. 1, pp. 890-902, 2001.

[74] K. Y. Lee, M. Li, D. R. Olsen, W. T. Chen, B. T. C. Tan, and S. Mhaisalkar, "Microstructure, joint strength and failure mechanism of $\mathrm{Sn}-\mathrm{Ag}, \mathrm{nnSn}-\mathrm{Ag}-\mathrm{Cu}$ versus Sn-Pb-Ag solders in BGA packages," 2001 Proceedings. 51 st Electron. Components Technol. Conf. (Cat. No.01CH37220), vol. 00, no. C, 2001.

[75] A. T. Wu, M. H. Chen, and C. H. Huang, "Formation of intermetallic compounds in SnAgBiIn solder systems on Cu substrates," J. Alloys Compd., vol. 476, no. 1-2, pp. 436-440, 2009.

[76] T. M. Korhonen, P. Su, S. J. Hong, M. a. Korhonen, and C.-Y. Li, "Reactions of lead-free solders with CuNi metallizations," J. Electron. Mater., vol. 29, no. 10, pp. 1194-1199, 2000.

[77] D. Cullen, W. Paw, J. Swanson, and L. Toscano, "Eliminating Microvoid Risk Via An Optimized Surface Finish Process," Proc. Int. Conf. Lead-free Solder., pp. 1-9, 2006.

[78] Y.-H. Yau, K. Wengenroth, and J. Abys, "A Study of Planar Microvoiding In Pb-Free Solder Joints," Hong Kong Print. Circuit Assoc., no. 22, pp. 1-14, 2007.

[79] R. Schueller, "Considerations for Selecting a Printed Circuit Board Surface Finish,” 2005.

[80] I. Florida CirTech, "Immersion Silver. Processing Guide for Printed Circuit Board Manufactrers," 2008. 